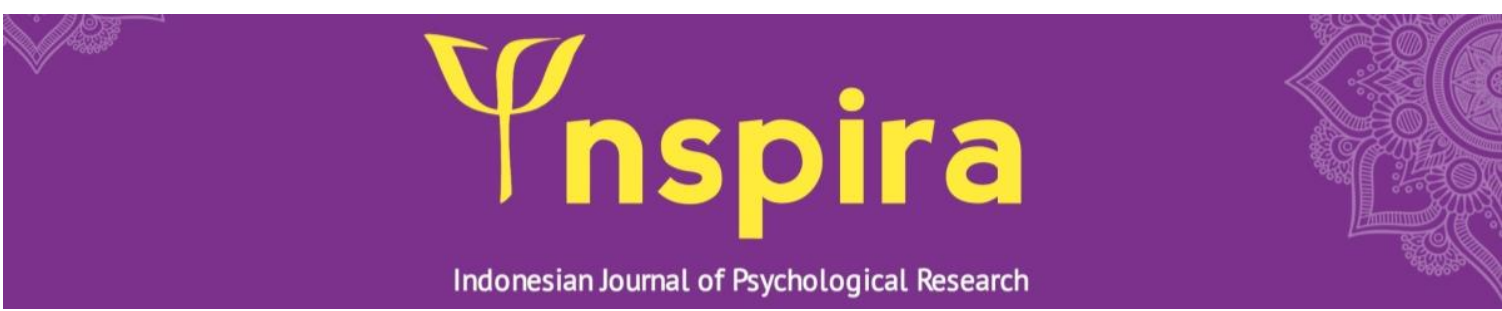

\title{
Who is more anxious in learning a foreign language: males or females?
}

Defira Afrianti ${ }^{1 凶}$, Mauloeddin Afna ${ }^{2}$

${ }^{12}$ Department of English Education, Institut Agama Islam Negeri Langsa, Aceh, Indonesia.

\section{$\triangle$ Corresponding author: \\ Defira Afrianti (email: defira.afrianti@gmail.com)}

\begin{abstract}
This study aims to investigate English speaking anxiety experienced by students on gender difference. This quantitative study applied a comparative design with 122 English students (male: $20,5 \%$ ) as a research sample using the proportionate stratified random sampling technique. The data were collected by Foreign Language Classroom Anxiety Scale by Horwitz that consist of 33 statements. By independent sample t-test, the result showed that the anxiety means a score of male students was 89,60, and the female was 93,24 , with a p-value of 0,203 . It indicated that the anxiety experienced by males and females was not significantly different.
\end{abstract}

\section{Article History:}

Received: August 25, 2020

Revised: September 8, 2020

Accepted: November 10, 2020

Published: December 28, 2020

\section{Keyword:}

foreign language anxiety; genderbased anxiety; situation-specific anxiety; state anxiety; trait anxiety

How to cite (APA $7^{\text {th }}$ Edition)

Afrianti, D. \& Afna, M. (2020). Who is more anxious in learning a foreign language, males or females? INSPIR A: Indonesian Journal of Psychological Research, 1(2), 49-56. https://doi.org/10.32505/inspira.v1i2.2877

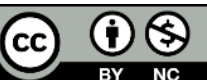

This is an open-access article distributed under the Creative Commons Attribution License, which permits unrestricted use, distribution, and reproduction in any medium provided the original work is properly cited. This is enabled under the terms of attribution and noncommercial usage of the material. (C2020 by Defira Afrianti \& Mauloeddin Afna. 


\section{INTRODUCTION}

Teaching English at school is not something new because it has been learned at the beginner level until the advanced level. Although English has been studied from the basic level, most Indonesian students still have a low capability in English. The report of EF Proficiency Index for school (2016), Indonesian position in 32 from 72 countries in the world. The fact above can further improve English capability, especially for students in University who want to be a good teacher in the future.

At the university level, primary English students learn more specifically about English. They know from the theory until teaching practice. In the class, they learn various ideas that are delivered in a written or oral text. The mastery of views should be equal to exercise. It is prepared for students to get supplies to practice using language in teaching. Every student receives many occasions to explore their speaking. It is expected that they become teachers who can train and transfer English skills to students in various levels of education. The primary goal of all English language teaching should be to give learners the ability to use English effectively and accurately in communication. However, not all language learners can speak fluently and accurately after many years of studying English because they lack the necessary knowledge.

Speaking activity can be interpreted as speaking activities to convey a message, idea, or opinion to an interlocutor; speaking activity is speaking in English. The main goals of speaking are to communicate. They are the sending and receiving of messages between one or more people. In speaking, it needs to be accurate in vocabulary use and pronunciation through controlled and guided activities and to be fluent, considered to keep going when speaking spontaneously. By showing the power of speaking English makes the teacher or other people give feedback on it.

Speaking is not only about related physical and skill but also determined by psychological factors, like self-confidence. Rakhmat (2005) states that if someone feels inferior, they will tend to communicate their ideas to the people and be afraid to express in front of many people because fear of others will blame them. Someone likely to be less confident wherever possible to avoid the situation of communication.

Speaking in a new language is not easy for a student who does not have high self-confidence. Speaking performance needs high confidence. In addition, low confidence is a factor of speaking anxiety. In this case, most English students are not confident in verbal communication. When they have to talk in front of the class, they will become anxious. They feel afraid of being abused when making mistakes. They are shy to try to speak English because of their pronunciation. The students who cannot show their ability to speak English will get worried in the class, which becomes a big problem. When the learners have high anxiety, worry, or fear in a foreign language class, they become difficult to acquire.

The unsuccessful students in speaking can be due to psychological aspect. Speaking anxiety is a fear of expressing oneself verbally, which physiological signs can recognize. Clement and Tupin claim that in Gaibani, the students tried to avoid speaking in public because of embarrassment, shaky voices, rapid heartbeat, discomfort, inferiority complex, and low selfrespect (Gaibani \& Elmenfi, 2014). The anxiety in speaking English implies the students not getting maximal performance in Speaking subjects. Stress experienced by a person when speaking in a foreign language was widespread in terms of Foreign Language Anxiety. 
Some expert-defined anxiety: In Horwitz et al. view in Cabansag (2013), there are three components of language anxiety: communication apprehension, test anxiety, and fear of negative evaluation. Anxiety is a universal human emotion. According to Suleimenova (2013), anxiety, distress, or uneasiness of the mind is caused by fear of danger or misfortune. General anxiety is the excessive and exaggerated worry about everyday things.

Maclntyre \& Gardner, as cited by Khan \& Zafar (2010) in the literature on the role of anxiety in second language learning, three general approaches have been identified: trait, state, and situation-specific perspectives. Trait anxiety refers to the stable predisposition to become anxious in a cross-section of situations. State anxiety is the transient, moment-to-moment experience of anxiety as an emotional reaction to the current situation. Situation-specific anxiety can be the probability of becoming anxious in a particular type of situation, such as during tests ("test anxiety"), when solving mathematics problems ("math anxiety"), or when speaking a second language ("language anxiety"). In terms of definition, several researchers have offered definitions of foreign language anxiety. In Tran (2012), Clement cited foreign language anxiety as a complex construct that deals with learners' psychology regarding their feelings, self-esteem, and self-confidence.

Many factors affect language learning, such as language learning environment, gender, personality, and affective factors. Many studies have been conducted about gender factors in foreign language learning (Şimşek, 2015). In a simple definition, gender is the essential identity of a human being. In a typical case, it is divided into two kinds, and they are male and female. Most of them are afraid of making mistakes, lack motivation, and lack communication with lecturers, making them nervous about speaking English. In most cases, students feel more comfortable speaking in their mother tongue since it is the language they have learned naturally.

A study about foreign language anxiety has been conducting by researchers. Surya, Menanti, \& Siregar (2018) discussed foreign language anxiety and its correlation to self-efficacy and the lecturer's assertive behavior. A few more research carried out a positive correlation between anxiety and gender. D'Souza, Sae-lee, \& Chanak (2016) supported it, who assumed that gender could also impact learning a foreign language. In other research, Hsu's (2012) research for the gender difference in public speaking anxiety around $60 \%(21.74 \%$ male, $39.13 \%$ female $)$ of the interviewed participants mentioned that they experienced anxiety before the speech. In addition, around 30\% (8.70\% male, $21.74 \%$ female) of the interviewed participants mentioned that they experienced anxiety during the speech. At the same time, only $10 \%$ (8.7\% female) participants mentioned that they experienced anxiety both before and during their speech. Further analysis has shown that female students are more prone to being grade-conscious and afraid of feeling inadequate in front of their classmates than male students.

The Akdeniz Language Studies Conference's results of the third research question revealed a significant difference between genders in terms of speaking anxiety level. Female students demonstrated a moderate level of anxiety, whereas male students experienced speaking anxiety at a low level. This finding supports the study conducted by Öztürk \& Gürbüz (2013), who investigated the relationship between foreign language speaking anxiety and proficiency level and found that female students experienced a higher level of speaking anxiety than male students. The other result from Armstrong \& Khawaja's (2002) research was a significant difference between the males' and females' self-reported anxiety symptoms, the extent and severity of these anxiety symptoms for the male group $(M=9.16)$ and female group $(M=13.75)$. 
Based on the resulting interview from the respondence, shows one source of speaking anxiety is gender. There are some reasons why gender becomes one source of speaking anxiety. Female and male students have different reasons why gender becomes a source of speaking anxiety. Female and male have different speaking topics; female students have different topics in speaking with the opposite sex. In addition, female students think that their English is terrible, and the opposite sex will think that female students are incompetent. Male students also have different reasons why they feel anxious to speak English to the opposite sex. They think that female students are more preserved than male students. However, the male student assumes that a different topic is also a factor of speaking anxiety (Antoro, Wisasongko \& Khazanah, 2015).

In Indonesia, English is used as a foreign language. The use of English as a foreign language tends to cause more anxiety than as a second language. This article was to investigate English speaking anxiety experienced by English department students on the gender difference in the context of Indonesia.

\section{RESEARCH METHOD}

This research was conducted using a quantitative approach and comparative research to know the comparative of English-speaking anxiety based on gender differences. In this study, the researcher took 122 of the fourth and sixth semester students of the Department of English Education, Institut Agama Islam Negeri Langsa as a sample by proportionate Stratified random sampling (25 male students and 97 female students).

Collecting data in this study is taken by using a questionnaire. The research instruments were distributed to the respondent. This method was used because the observed variables are psychological inside of the respondent. To measure the level of foreign language anxiety that interrupts students, the researcher using the Foreign Language Classroom Anxiety Scale (FLCAS) developed by Horwitz, Horwitz \& Cope (1986). This scale consist of 33 statements consists of three aspects: communication apprehension, test anxiety, and fear of negative evaluation. To ease the respondents' answering, the researcher translated into participants' mother tongue and adapted it to suit different needs. The research instruments were distributed to students as respondents to know students' anxiety. They will respond about their experience in oral performance by self-assessment. Kind of instrument this study is an inventory with the Likert Scale. Likert developed the principle of measuring attitudes by asking people to respond to a series of statements about a topic regarding the extent to which they agree with them and exploit them into the cognitive and affective components of attitudes. These ordinal scales measure levels of agreement/disagreement. It is most commonly seen as a 5-point scale ranging from "Strongly Agree, Agree, Neither, Disagree and Strongly Disagree" Each level on the scale is assigned a numeric value, usually starting at one and increased by one for each level. This research was using a 4-point scale, and this is done to get accurate answers and to eliminate the uncertainty.

Data analysis is the process integrated into a research procedure. Data analysis was done to prove or find answers to the formulation, and researcher's hypothesis about the variables studied. The researchers' analysis will be read or interpreted by the researchers and then based on empirical reality. This research used inferential statistics with parametric to conclude and based on analysis of the sample data, and the result can be applied to the population. After 
analysis of classical assumptions fulfilled, the next step is testing the hypothesis with compare mean and using an independent sample t-test with the program of software IBM ${ }^{\circledR}$ SPSS $\mathbb{}$ Statistics version 23.0 for Windows. This test was used to determine the difference in mean scores between the two groups of samples.

\section{RESULT}

To describe the result of the research to provide an overview of the research subject, the researcher set the criterion of categorization of the foreign language anxiety scale. The research subject was categorization by using the principle of the standard curve that was decided into five categories: very low, low, medium, high, and very high.

Table 1. Hypothetic Score and Empiric Score of Research

\begin{tabular}{ccccccccc}
\hline \multirow{2}{*}{ Variable } & \multicolumn{4}{c}{ Hypothetical Score } & \multicolumn{4}{c}{ Empirical Score } \\
\cline { 2 - 9 } & Min & $\max$ & mean & SD & Min & Max & mean & SD \\
\hline FLA & 33 & 132 & 82,5 & 16,5 & 56 & 129 & 92,49 & 12,715 \\
\hline
\end{tabular}

The data presented in table 4.3 show that the mean hypothetic in the variable of anxiety is 82,5 and score mean of empiric as much as 92,49 . Then, the comparison showed that the mean empiric is higher than the mean hypothetic $(92,49>82,5)$. It is shown that anxiety in English speaking on the research subject high. Furthermore, the use of categorization subject of research as presented in table 4.2, from the measurement variable of anxiety, decides the category shallow, low, medium, high, and very high. Before testing the hypothesis, some requirements must be filled to make sure data used to be analyzed, which is the assumption in statistics parametric. Therefore, it must do some tests to conclude that taken not deviate from the truth. Testing is carried out normality test and the homogeneity test.

Normality test is used in this research is in procedure Kolmogorov Smirnov test. If sig $>\alpha$ $(0,05)$, then the data in a normal distribution. On the contrary, if $\operatorname{sig}<\alpha$, the data is not normal. the statistic of Kolmogorov Smirnov was 0,062 and sig. 0,200 (sig > 0,05). Thus, it can be concluded that anxiety is a normal distribution.

The homogeneity test was used SPSS with Levene statistic, the Levene test used to test the similarity of the variance of some of the population. If the value of Levene statistic $>0,05$, it means that a variety of data is homogenous. The real significance is 0,520 , and it is showing that sig $>0,05$, thus the data is homogeneous.

Based on the descriptive study had done, the resulting anxiety from 25 male students in very high category of anxiety as much as two students, high category ten students, low category three students and medium category ten students. Percentage of the data can see from the diagram below: 

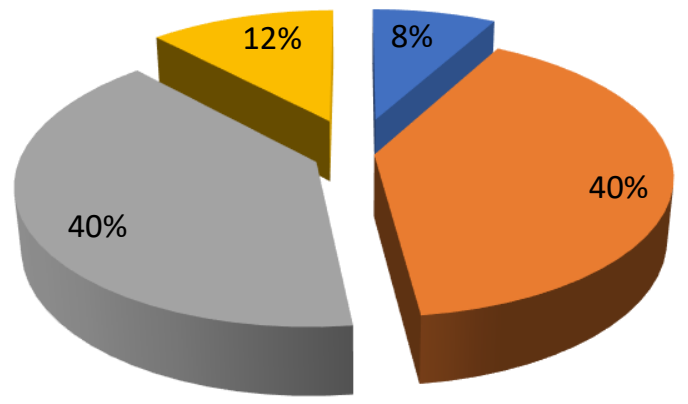

\author{
very high \\ high \\ medium \\ $\square$ low \\ very low
}

Figure 1. Anxiety level of male students

The resulting anxiety from 97 female students was in the very high category as much as 14 students, high category 46 students, medium category 27 students, low category nine students, and very low one student. Percentage of the data present by diagram bellow :

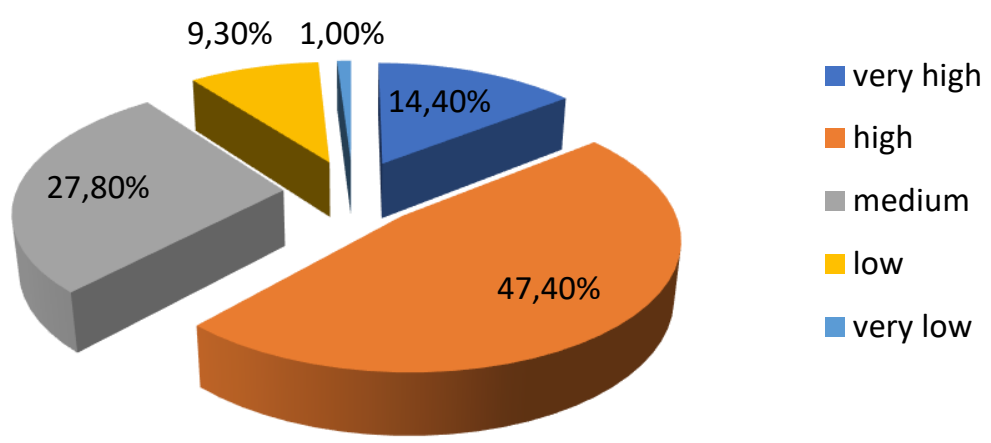

Figure 2. Anxiety level of female students

From the explanation above, the anxiety experienced by female students is more varied compared with male students. It was evident from the result of analysis data score of range male students $<$ score of range female students: $43<64$ and score of deviation standard of male students $<$ deviation standard of female students: 11,321 <13,00.

An independent sample t-test does it with the program of software IBM ${ }^{\circledR}$ SPSS $®$ Statistics version 23.0 for Windows. The independent sample t-test was used to compare the mean of team groups to determine whether there is a significant difference between the mean score of male and female students. The result of the independent samples test present in Table 4.6 below:

Table 2. Independent Sampe T-Test

\begin{tabular}{cccccccc}
\hline Variable & F & sig & t & df & sig & $\begin{array}{c}\text { Mean } \\
\text { difference }\end{array}$ & $\begin{array}{c}\text { Standard of } \\
\text { Error }\end{array}$ \\
\hline FLA & 0,417 & 0,520 & $-1,279$ & 120 & 0,203 & $-3,637$ & 2,845 \\
\hline
\end{tabular}

Based on the result, the calculations are presented in the table above. A score of F obtained a value of 0,417 with sig $=0,520$. To testing the meaning F score, it has to stand on the score of the t-test. If score sig- F $>0,05$, it must stand on the Equal Variance Assumed table. While, if 
sig $<0,05$, it stands on a table of Equal Variances not Assumed. From the table above total significance of $F$ test $(0,520)>0,05$. Thus, in this research score of the $t$-Test stand on the table of equal variances assumed. On these table was getting t score $=-1,279$ with sig $=0,203$, if sig $>0,05 \mathrm{H}_{0}$ rejected. The result above was getting $\mathrm{t}=1,279$ with sig $(0,203)$. This research significance of t-test 0,203 $>0,05$ shows that there was no difference in speaking English anxiety based on gender.

\section{DISCUSSION}

Anxiety is one of the psychological factors that are very important in learning a language. Krashen (1982) mentions at least 3 points that affect a person's success in learning a language: motivation, confidence, and anxiety. The psychological aspect that hinders learning the language is referred to by the term affective filter. It was referred to the tendency of a person who has an attitude not optimal in learning the language, and it caused the person is not maximal in learning a language. In contrast, if she/he has an attitude that is conducive to learning the language will have an impact on optimal results in learning a language. This looks at someone who studied the language stressfully; all comprehension and preparations be troubled. Littlewood asserts that a foreign language classroom can create inhibitions and anxiety easily (Tuan \& Mai, 2015)

Gender differences were often debating related to the experience of learning foreign language anxiety. Behnke's research was discovered that female speakers reported higher anxiety patterns. Fariadian stated that male respondents demonstrated higher levels of language anxiety than female students (Fariadian, Azizifar, \& Gowhary (2014).). In contrast, Alsowat (2016) found that gender did not significantly impact foreign language anxiety in the current study. Many factors of anxiety cause it and these factor of male and female has a different portion. While Tòth was concluding some factors contribute to anxiety, such as 1) the nature of foreign language communication, 2) personality and character, 3) being foreign language major, 4) classroom situation, teachers, and peers, 5) target language competence, 6) instructional practice, and 7) lack of authentic communication. Personality factor is one of the internal factors which significantly influence speaking anxiety by everyone.

\section{CONCLUSION}

This research showed the anxiety in using English as a foreign language experienced the students tended to be in high level. However, there is no significant difference between a male and female student in feeling anxiety when contacting English as a foreign language. These findings should be investigated further by considering other related factors, such as culture and personality.

\section{REFERENCES}

Alsowat, H. H. (2016). Foreign Language Anxiety in higher education: A practical framework for reducing FLA. European Scientific Journal, 12 (7), 193-215.

Antoro, I. W., Wisasongko, Khazanah, D. (2015). Speaking Anxiety: Factors Contributing To the Anxiety in Speaking Class of the First Year Students of the English Department Faculty of Letters, Jember University. [Undergraduate thesis, Universitas Jember] 
Armstrong, K. A. \& Khawaja, N. G. (2002). Gender differences in anxiety: An investigation of the symptoms, cognitions, and sensitivity towards anxiety in a nonclinical population. Behavioural and Cognitive Psychotherapy, 30, 227-231.

Cabansag, J. N. (2013). English language anxiety and reading comprehension performance of college students in a state university. Researchers World: Journal of Arts, science \& Commerce, $4(4), 20-39$.

D’Souza, J. B., Sae-lee, P., \& Chanak, A. (2016). The influence of culture, gender and academic achievement on foreign language anxiety. Australian Journal of Sustainable Business and Society, 2(1), 20-31.

Fariadian, E., Azizifar, A. \& Gowhary, H. (2014). Gender contribution in anxiety in speaking EFL among Iranian learners. International Research Journal of Applied and Basic Sciences, 8(11), 2095-2099.

Gaibani, A. \& Elmenfi, F. (2014). The role of gender in influencing public speaking anxiety. British Journal of English Linguistics, 2(3),7-13.

Horwitz, E. K., Horwitz, M. B., \& Cope, J. (1986). Foreign language classroom anxiety. The Modern language journal, 70(2), 125-132.

Hsu, T. (2012). A study on the EFL students' speech related anxiety in Taiwan. International Journal of Research Studies in Language Learning, 1(2), 3-18.

Khan, Z. A., \& Zafar, S. (2010). The Effects of anxiety on cognitive processing in English language learning. English Language Teaching, 3(2), 199-209.

Krashen, S. (1982). Principles and practice in second language acquisition. Pergamon Press Inc.

Öztürk, G., \& Gürbüz, N. (2013). The impact of gender on foreign language speaking anxiety and motivation. Procedia-Social and Behavioral Sciences, 70, 654-665.

Rakhmat, J. (2005) Psikologi komunikasi. PT Remaja Rosdakarya.

Suleimenova, Z. (2013). Speaking anxiety in a foreign language classroom in Kazakhstan. Procedia-Social and Behavioral Sciences, 93, 1860-1868.

Surya, D., Menanti, A., \& Siregar, N. S. S. (2018). The relationship between self-efficacy and lecturer's assertive behavior with foreign language anxiety. ENLIGHTEN: Jurnal Bimbingan Konseling Islam, 1(2), 150-164.

The world's largest ranking of English skills (edition 6), http://www.ef.co.id/epi/2016

Tran, T. T. T. (2012). A review of Horwitz, Horwitz and Cope's Theory of Foreign Language Anxiety and the challenges to the theory. English Language Teaching, 5(1), 69-75.

Tuan, N. H. \& Mai, T. N. (2015). Factors affecting students' speaking performance at Le Thanh Hien High School. Asian Journal of Educational Research, 3(2), 2311-6080. 